\title{
Minimizing cold ischaemia time: assessing the effect of different factors at a single renal centre
}

\section{North Bistol Wits \\ Histist}

\author{
DM Evans, L Read, J Vaz, NK Hamilton \& D Munro \\ Directorate of Renal Medicine \\ Southmead Hospital, North Bristol NHS Trust, Bristol
}

P0145

\section{Introduction}

Cold ischaemic time (CIT) is an important modifiable risk factor for renal transplant graft survival. Within our centre in Bristol we have reviewed how certain factors affected the CIT (both negative and positively).

\section{Methods}

This audit was initially carried out in 2008 and we wanted to review progress with some changes

in practice and how factors influence the transplant pathway. Not all factors from the 2008 audit were relevant so we chose to re-audit: (1) Mean time for transit of samples from clinical area to laboratory (2) Patient suitability for Virtual Cross-match VXM (3) Mean delays accessing operating theatres (readiness deemed to be when patient/organ on site and cross-match negative and able to proceed)

\section{$\underline{\text { Results }}$}

\section{Criterion}

Transit of

Specimens

$\%$ Virtual

Cross-matches

Time deemed

ready for

Theatre \& time minutes

Theatres

accessed

$\begin{array}{lll}\text { CIT } & 16 \text { hours } & 13 \text { hours } 41 \\ & 36 & \text { minutes } \\ \text { minutes } & \end{array}$

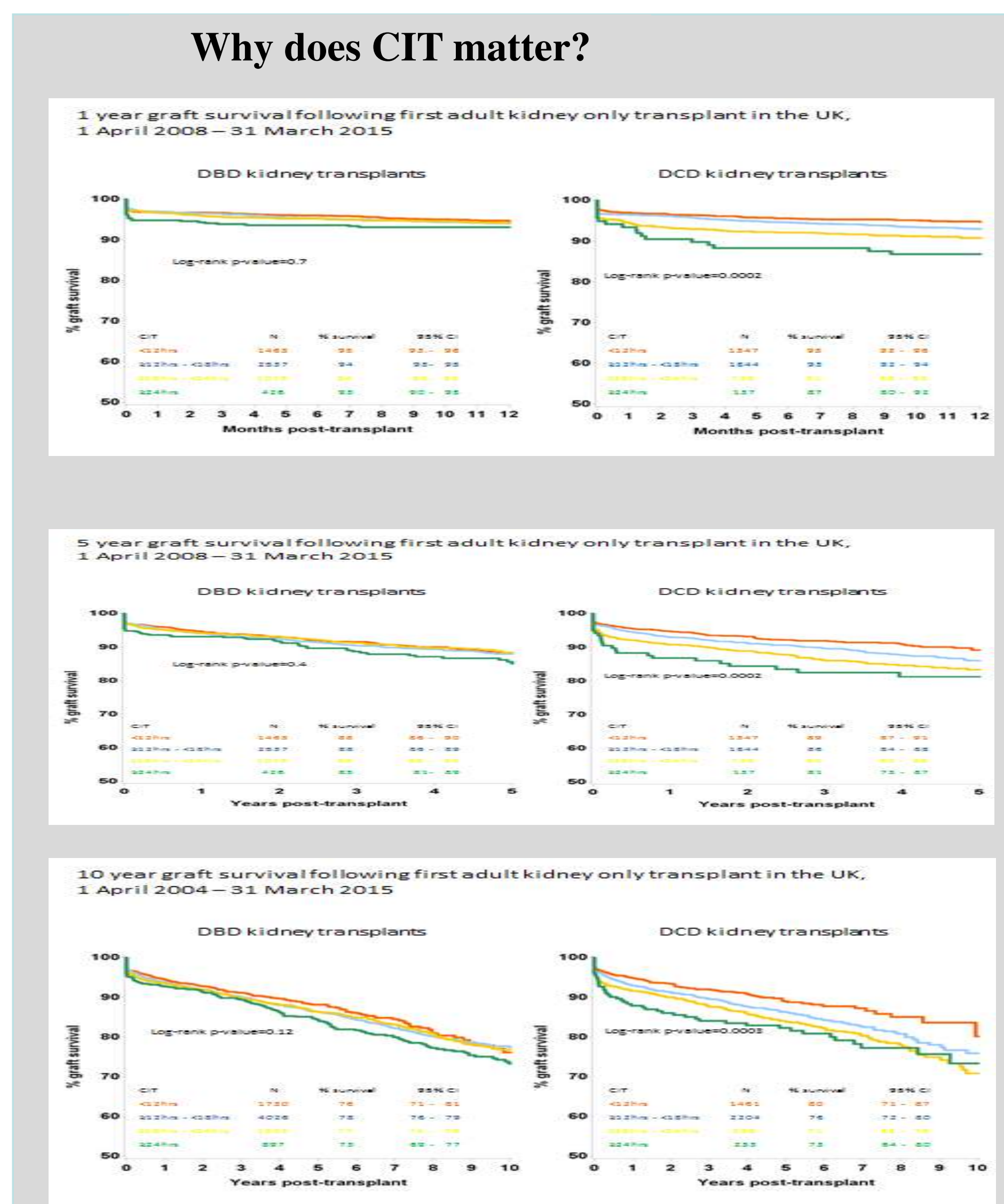

Data supplied by Statistics Department, NHSBT

\section{Discussion/Conclusion}

Sample transit time essentially unchanged as solid system insitu and working well. The advent of VXM has reduced CIT most. It is completed in advance before patient or organ are on-site. It is dependent on sensitisation, recent samples and results. It has reduced cross-match reporting from $6+$ hours to as little as 15 minutes. The move to our new hospital building

has made accessing theatres problematic - with more specialities requiring emergency access and priority. Despite the delay from "Ready-to-go" and time "Actually-in" theatres overall the CIT has reduced significantly. This delay has been

cancelled-out by the reduction achieved by the VXM. We continue to "chip- away" at our CIT - this is only possible due to the diligence of the multi-disciplinary team. The stats above

kindly provided by NHSBT demonstrate up to an $8 \%$ difference in 1 and 5 year graft survival $<24 \mathrm{hrs}$ or $>24 \mathrm{hrs}$ (NHSBT, 2016) 